\title{
Labor management strategies in facing the economic crisis. Evidence from Greek livestock farms
}

\author{
Athanasios Ragkos*, Stavriani Koutsou**, Alexandros Theodoridis***,

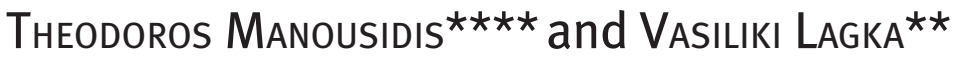

DOI: $10.30682 / \mathrm{nm} 1801 \mathrm{f}$

JEL codes: Q12, Q18

\begin{abstract}
This paper investigates the role of labor - either family or hired - in the development of the Greek livestock sector and the effects of labor management strategies undertaken against the crisis. For this purpose, the main types of cattle and sheep and goat farms were investigated with a questionnaire survey and their strategies were assessed. Building on the findings from four studies of different production sectors and systems, important questions about the role of hired labor in the Greece of crisis are raised and dealt with. Intensive farms profited from hired labor in order to develop, but during the crisis they demonstrated a variety of strategies. On the other hand, extensive systems safeguarded their family character and took advantage of traditional knowledge in order to survive the crisis. The labor from female family members was proven a significant asset for many of the surveyed farms.
\end{abstract}

Keywords: Farm management, Farm sustainability, Family farming.

\section{Introduction}

There is a massive body of literature examining the factors governing the survival of European family farms under difficult economic, social and historic conditions, despite their low economic performance which cannot justify their operation under purely economic criteria (Jervell and Jolly, 2003; Casini et al., 2004). Besides the inherent incline of agriculture to experience crises, the trajectory of the agricultural and livestock sector in Greece since the 1990s has also pointed towards that direction. First, ever since 2003 the input price index has been higher than the output price index, while from 2009 to 2012 production costs increased by 22.5 per cent (PASEGES, 2013); the most burdened inputs were the ones crucial to livestock production i.e. feedstuff ( 31 per cent increase) and energy (64 per cent increase). Second, the general lack of liquidity has been a cause of financial suffocation for livestock farms; dairy industries were unable to remunerate farmers on time, which resulted in referred payments to banks and input suppliers (Karelakis et al., 2013). Third, the sector had to face its chronic structural drawbacks (small average farm size, lack of modernization, high dependence on subsidies, low level of

\footnotetext{
* Agricultural Economics Research Institute, ELGO Demeter, Greece.

** Department of Agricultural Technology, Alexander Technological Educational Institute of Thessaloniki, Sindos, Thessaloniki, Greece.

*** School of Veterinary Medicine, Faculty of Health Sciences, Aristotle University of Thessaloniki, Thessaloniki, Greece.

**** Department of Agricultural Development, Democritus University of Thrace, Orestiada, Greece.

Corresponding author: ragkos@agreri.gr.
} 
cooperation), which were disregarded in the past due to the prosperous general environment (Karanikolas and Martinos, 2012).

The mitigation of the adverse effects of the crisis would predominantly involve changes in the strategies that farmers follow in their use of inputs (land, labor, and capital). Diversification (Meert et al., 2005) is one of the most common strategies adopted by farmers not only after the occurrence of an external shock ("remedial" strategies), but also before that in order to increase their resilience ("preventive" strategies) (Milestad et al., 2012). Lemery et al. (2005) and Ingrand et al. (2006) proposed a useful typology of those strategies as active (Agir sur) or passive (Faire avec). Active strategies face crises directly with clear visions of the future state of the farm, including more use of resources (for example new investments), better internal organization and the development of efficient mechanisms to increase its ability to confront uncertainty. Passive strategies rely on existing - or even reduced levels of resource use, past experiences and already known tools in order to help farms defend themselves against a crisis, regardless whether they will be able to return to their pristine state or not.

Because of the current crisis, Greek farms are now deprived of their access to capital and - in some cases - they are unable to manage their investments, as will be shown in this paper. Under these circumstances, diversification strategies in the use of labor (family or hired) are important - or the only - crisis-aversion mechanisms. Karelakis et al. (2013) found that sheep and goat farmers in North-Eastern Greece followed a bundle of aggressive and passive strategies, depending on their characteristics; re-arrangements in the use of labor were important elements of some of these strategies.

This paper examines the various strategies that Greek cattle and sheep and goat farms undertook for labor management in order to face the crisis. The structural and development characteristics of these sectors are investigated alongside with the various roles that labor - either family or hired has played in their development and in the management strategies that they undertook against the crisis. Empirical findings demonstrate whether there is a "role model" against the crisis and which are the "best practices" against unexpected economic occurrences. The analysis and discussion is based on the findings of four studies (Table 1) which focus on different sectors and production systems of the Greek livestock economy: intensive dairy cattle, intensive sheep, semi-extensive (pasture-based) sheep and transhumant sheep and goat. The Table includes the basic characteristics of each sector, the methodological framework and the geographical context.

\section{Literature review - Labor in agriculture un- der difficult conditions}

\subsection{Labor and farm diversification}

Three types of diversification are presented by Meert et al. (2005) and are characterized as "agricultural", "structural" and "income" diversification respectively. In what follows, these strategies are discussed with particular focus on the role of labor management in livestock farms.

Agricultural diversification involves the management of capital or labor in order to reduce operational costs. The latter case includes strategies such as the substitution of capital by labor and the increase of the involvement of the farm family. Family-based extensive systems have the ability to survive more easily during periods of adverse external conditions due to low capital endowments, the use of excessive family labour and their ability to decrease their standards of living. Based on this, family-based production systems can resort to unpaid family labor while they expect circumstances to ameliorate (Holzner, 2008). This is also supported by the recently witnessed phenomenon of return of young family members to rural communities and family farms, due to high unemployment in other sectors (Goussios, 2011). Reciprocal labor (Donaldson, 2011) could be considered as a form of agricultural diversification for small family farms, if resorting to help from neighbouring farms could be considered a cost-saving alternative to hired labor. This type of diversification requires cooperation, which is not always the case in the Greek setting, considering the low social capital endowments that have been reported for the country (Paraskevopoulos, 2006; Kazakos, 2006). Another example of the sort involves changing the breed of animals reared and, consequently the production system. Marta-Costa (2010) who exam- 
ined how rearing local or improved breeds affects the sustainability of farms, showing that although a local cattle breed performed better in terms of environmental sustainability, it lacked social and economic sustainability.

If farms do not follow agricultural diversification, they have the option of structural diversification. In livestock farms this would entail a reduction of flock size or part-time farming. Cooperation may also be included in this category: farmers resort to collaborative schemes in order to reduce the impact of external turbulences. Cessna (2010) reported that the USA not only responded to a crisis in 2007-2008 by reducing the U.S. dairy herd by about 201,000 cows, but also this strategy was implemented through the National Milk Producers Federation.

Income diversification involves off-farm employment of farmers and their family members (pluriactivity) (Franks, 1998) in order to ensure the reproduction of the family farm by generating alternative sources of income. Jette-Nantel et al. (2011) discussed the benefits from off-farm employment by arguing that the expansion paths of farms are decided also by taking into account opportunities or existing employment in off-farm sectors, while off-farm labor may assist large farms to increase their flexibility or to make non-agricultural investments. When it comes to women, Bharadwaj et al. (2013) reported that they preferred to work offfarm in order to contribute to the financial stability of the farm, but this was also, inter alia, a matter of individual preferences and farm-specific characteristics. Income diversification can be proven rational when the opportunity cost of off-farm employment is high, for instance in rural areas where there are plenty of off-farm jobs. This phenomenon has been discussed for Albania by Guri et al. (2014), regarding the massive rural exodus after the fall of the Communist regime. The authors found that this phenomenon, which was due to socioeconomic and political developments, did not affect land tenure substantially, as family members who did not migrate continued to work on family farms. However, under the current state of the Greek economy, with a generalized crisis affecting all sectors, this condition is not met, so income diversification is not a suitable strategy. As will be shown in what follows, this type of diversification was adopted before the crisis, in order to increase the sources of income of the farm family and reduce farm-related risks and (Jette-Nantel et al., 2011). Unlike times of prosperity, times of widespread recession signal a return of workforce to agriculture, generating an agricultural diversification pattern rather than an income diversification one.

\subsection{Particularities of labor in livestock farms}

There are three elements characterizing the employment in livestock production in Southern Europe and in Greece alike. The first concerns the prevalence of hired labor from migrant workers, which only recently occurred in Greece, but was a common phenomenon in Western Europe and other Northern Mediterranean countries. Not only have foreign workers supported livestock production in these countries, but they have rather been the ones keeping it alive (Kasimis and Papadopoulos, 2005; Nori and DeMarchi, 2015). In times of prosperity migrants are the ones filling in the available vacancies in the labor market, thus facilitating the development of various sectors including, of course, agriculture, but in times of crisis they tend to move to other - more prosperous - settings, thus alleviating the difficult situations that may occur in the labor market or in the general economy (Zaiceva and Zimmermann, 2016). Nowadays they play multiple roles in rural territories, not only economic (construction and maintenance) but also social (participation in traditional/cultural life) (Kasimis and Papadopoulos, 2005; Nori, 2016).

The second important element is the labor of female family members. In general, women were ruled out of the operation of family farms during the post-war period, as the productivist model led to a "masculinisation" of farming (Saugeres, 2002). Combined with an abundance of hired labor, women were assigned an auxiliary role and looked for employment in non-farm sectors (Bharadwaj et al., 2013) or remained within their household duties. With women away from the production process, however, it was difficult to continue performing some of the tasks in the same efficient way, as womens' labor is endowed with particular emotional elements "crucial for the sustainability of rural people and places" (Herron and Skinner, 2012). In this aspect, Trauger (2004) underlined 
the fact that women are up to three times more likely to operate a sustainable farm, demonstrating their persistence to quality and to the performance of multiple non-economic functions through their engagement in the primary sector.

The third element of importance for livestock production is the high level of skill required to be a worker in a livestock farm. In intensive systems, workers are expected to be familiar with modern technologies and automated systems, as well as with innovative animal health and product quality monitoring methods; in addition, heads-of-farms need to anticipate market conditions, to maintain a high level of farm education, communication and information, to keep detailed records of economic and managerial tasks and to use computers, internet-based applications or other Information and Communication Technologies. In extensive systems such skills and knowledge are useful, but also need to be supplemented with a very good knowledge and understanding of nature, local flora and fauna as well as with methods to resolve unexpected situations when being exposed to dangers e.g. predators, weather etc. During the centuries, livestock farmers have evolved very important and detailed tacit knowledge concerning these issues. This type of knowledge can not only be integrated to modern practices, but may also remain intact through years, persisting through changes and evolving rather than changing or being altered (Reyes-García et al., 2014). Tacit knowledge has also been reported as an element of the adaptive capacity of an agricultural production system (von Glasenapp and Thornton, 2011). Despite the fact that these knowledge endowments are important for livestock farms, migrant workers are not always experienced in such settings and need proper training (usually informal) during the first period of their employment. Nonetheless, recent evidence demonstrated that Greek livestock farmers look for workers with such skills and prioritize them, although they are hard to find (Nori and Ragkos, 2017).

\subsection{The role of labor in the Greek livestock sector}

It has been traditionally difficult for Greek livestock farmers to find workers. Even from the inter-war period, a job as a hired worked in a peer fellow's farm was considered as a sign of poverty or incompetence (Loukopoulos, 1930). Under this situation and also in view of the harsh socio economic and historic conditions that rural Greece had faced until the end of World War II, the role of family labor was essential not only for the smooth operation or expansion of livestock farms, but rather for their mere survival. The unpaid labor of family members (husband, wife, children and other persons with kinship relationships) was the main source of flexibility for these farms, which were able to resort to their own labor resources in order to survive difficulties (Holzner, 2008). During the post-war period, the lack of family labor (partially due to massive migratory movements) led to the prevalence of small and medium-sized livestock farms in Greece; these developments have been discussed previously by numerous authors (see Kasimis and Papadopoulos, 2013, for an integrated discussion). It was after the 1990s that the abundance of labor from foreign migrants led to the emergence of large-sized intensive livestock farms, which took advantage of the very low costs of hired labour (Karanikolas and Martinos, 2012), a situation unknown - as it seems - up to then. As Maroukis (2013) pointed out for the whole Greek economy "the overall availability of cheap, informal and flexible migrant labour has been a key factor in maintaining a low cost for the reproduction of the familistic welfare capitalism". This flexibility of hired labor was also, in some cases, a source of abuse (Kasimis and Papadopoulos, 2005).

Apart from the availability of cheap labor, farms were privileged by Common Agricultural Policy (CAP) measures and were ideal for the modern living standards that had already started to penetrate Greek rural areas (better working conditions, more systemized work plan etc). For the following 20 years the circumstances were favourable for the expansion of the livestock sector, as there was abundant labor supply and enough capital to support it, which are both prerequisites for such type of development (Donaldson, 2011). However, the reduced profitability of farms during the crisis brought a decrease in migrant labor in Greece: from 2009 to 2013 a 4.6 per cent reduction was witnessed in the number of permanent hired workers and a $13.6 \%$ reduction in seasonal hired labor in the Greek primary sector. 
During the crisis, hired labor has not been used in a uniform pattern by all types of livestock farms.

\section{Four studies of the Greek livestock sector}

This paper builds on the stories told by the different trajectories of livestock farms in Greece concerning their labor management strategies. The livestock sector in Greece contributes 28.3 per cent to the total added value of its primary production and almost 1 per cent to national GDP (ELSTAT, 2015, PASEGES, 2013). Sheep and goat farming constitutes the most important livestock production activity followed by bovine production; these sectors vary significantly according to their orientation and level of intensification from semi-extensive to intensive (Chatziminaoglou, 2001). Data were gathered through a survey of the main types of livestock farms - intensive dairy cattle, intensive sheep, semi-extensive (pasture-based) sheep and transhumant sheep and goat -, in order to investigate the different roles of family and hired labor in determining their resilience and vul- nerability before and after the crisis. The survey was conducted in Macedonia, Thrace and Thessaly (Northern and Central Greece) (Figure 1). The basic background information for each survey is reported in Table 1.

A questionnaire was used to record the main technical and economic data regarding the operation and management of the farms: flock size and structure, land use and percentage of grazing, fixed capital endowments (buildings, machinery), variable expenses (veterinary, purchased feedstuff and inputs etc), labor availability and requirements, productivity and product prices. Care was taken to record changes in the use of family and hired labor and also differences in the allocation of tasks among workers or other qualitative elements of farm labor.

\subsection{Intensive dairy cattle farming in Northern Greece (Study 1)}

The first survey concerns the dairy cattle sector, which witnessed severe intensification: during the decade 2003-2013 the average milk production by

Figure 1 - Map of the geographical context of the four studies.

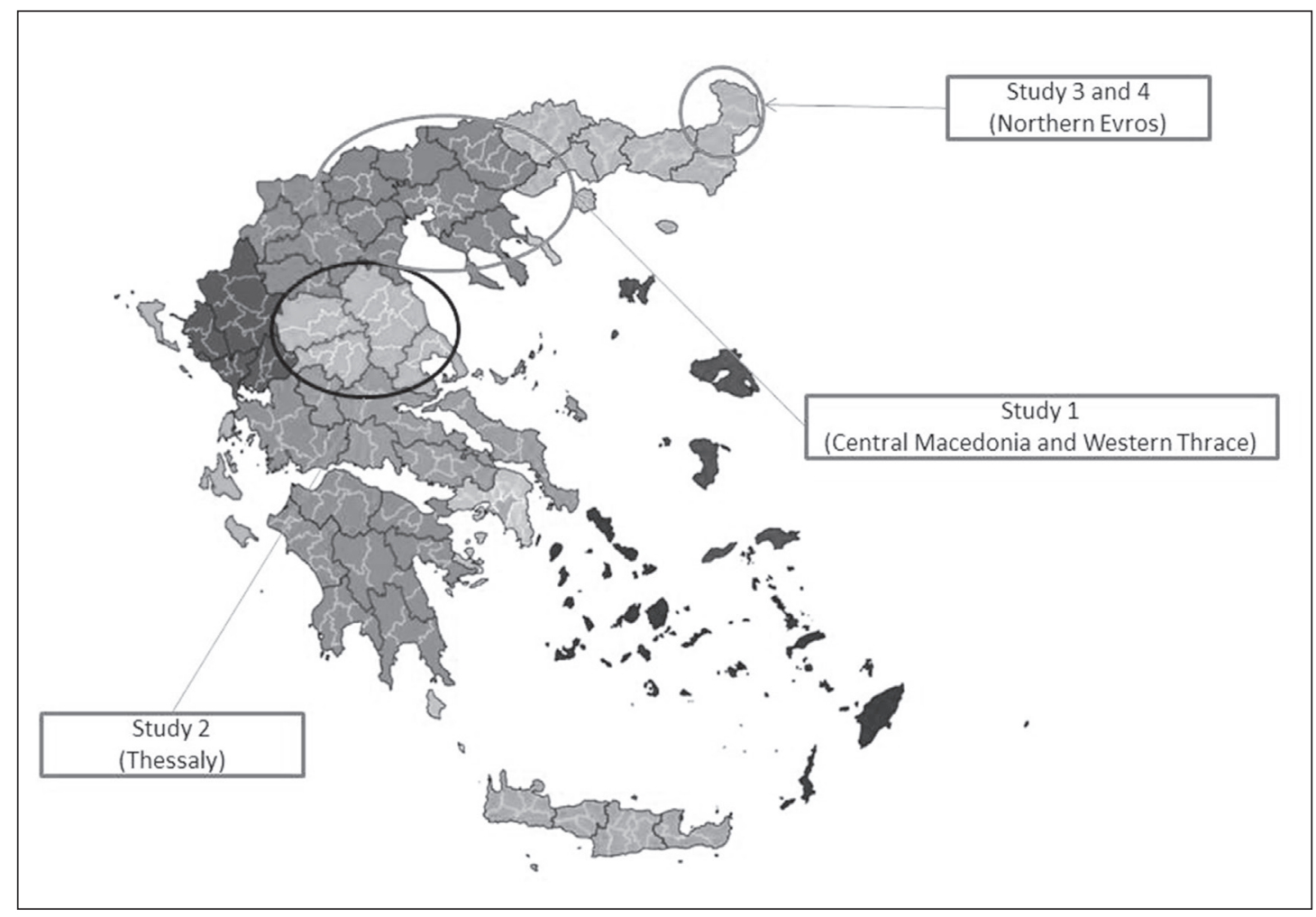


Table 1 - Profile of the four exemplary studies.

\begin{tabular}{|l|l|l|l|}
\hline \multicolumn{1}{|c|}{ Survey } & \multicolumn{1}{|c|}{$\begin{array}{c}\text { Geographical } \\
\text { area }\end{array}$} & \multicolumn{1}{|c|}{ Questionnaire survey profile } & System organizational characteristics \\
\hline Dairy cattle & $\begin{array}{l}\text { Northern Greece } \\
\text { (Macedonia) }\end{array}$ & 39 dairy cattle farms (2015) & $\begin{array}{l}\text { Intensive dairy cow production, high } \\
\text { investments, entrepreneurial farms }\end{array}$ \\
\hline $\begin{array}{l}\text { Sheep } \\
\text { and goat } \\
\text { transhumance }\end{array}$ & $\begin{array}{l}\text { Central Greece } \\
\text { (Thessaly) }\end{array}$ & $\begin{array}{l}121 \text { farms (winter in Thessaly, } \\
\text { summer in Thessaly, Macedonia } \\
\text { or Epirus) (2012-2013) }\end{array}$ & $\begin{array}{l}\text { Sheep and goat transhumant farms } \\
\text { spending winter in Thessaly. Semi- } \\
\text { intensive in winter, semi-extensive in } \\
\text { summer. Diversity of products (milk, } \\
\text { meat, cheese) }\end{array}$ \\
\hline $\begin{array}{l}\text { Intensive } \\
\text { sheep farming }\end{array}$ & $\begin{array}{l}\text { North-Eastern } \\
\text { Greece (Northern } \\
\text { Evros - lowlands) }\end{array}$ & $\begin{array}{l}\text { The survey was conducted in } \\
\text { in 2010 (start of crisis) and repeated } \\
\text { farms }\end{array}$ & $\begin{array}{l}\text { Intensive sheep farms, most of which } \\
\text { emerged after 2000s. High investments } \\
\text { and modern infrastructure }\end{array}$ \\
\hline $\begin{array}{l}\text { Extensive } \\
\text { sheep and } \\
\text { goat farming }\end{array}$ & $\begin{array}{l}\text { North-Eastern } \\
\text { Greece (Northern } \\
\text { Evros - } \\
\text { highlands) }\end{array}$ & 41 livestock farms (2012) & $\begin{array}{l}\text { Extensive sheep and goat and/or cattle } \\
\text { farms based on grazing. High level } \\
\text { of self-consumption. Many husbands } \\
\text { choose to work off-farm }\end{array}$ \\
\hline
\end{tabular}

farm was more than doubled, as the total production fell by $6.5 \%$ or by $0.7 \%$ annually while the number of farms was reduced by $57 \%$ which corresponds to $8.2 \%$ annual rate of decrease. As a result, many of the average sized semi-intensive farms of the past decades ceased to operate or transformed to large specialized dairy farms of entrepreneurial nature. In order to accommodate their rapid expansion, they resorted to hired labor, because family labor was not enough for intensive production and because of the new and very demanding managerial tasks that the heads-of-farms had to undertake because of the entrepreneurial transformation of the farm. Data from a survey in Northern Greece, showed that the labor requirements of the 39 sampled dairy cattle farms were covered almost equally by family members and hired workers (Table 2).
Dairy farmers undertook active strategies to face the crisis, including the increase of flock size: it was common not to sell any of the young calves but to maintain them in order to expand their flocks. The employment of even more migrant workers did not seriously affect the farm costs, which remained heavily capital-intensive as the labor costs do not exceed $8.4 \%$ of the total costs. The farms use 22 hours/cow less than ten years ago (Theodoridis and Psychoudakis, 2008), indicating that dairy farms utilize economies of scale and exhibit a higher level of organization. In economic terms this was due to the fact that large farms managed to maintain fairly acceptable milk prices when negotiating with dairy industries. However, the extension of shelf-life of fresh milk to 7-11 days in the Greek market has now allowed massive imports of milk from other

Table 2 - Main technical and economic performance indicators of dairy cattle farms.

\begin{tabular}{|l|c|l|c|c|}
\hline \multicolumn{2}{|c|}{ Technical and economic indicators } & \multicolumn{3}{c|}{ Production cost breakdown } \\
\hline Average size (number of cows) & 140.4 & & $\epsilon$ & $\%$ \\
\hline Milk production (ton./year) & 1118.3 & Land (Rent) & $15,390.9$ & 2.7 \\
\hline Mean milk price (€/kg) & 0.447 & Labor (Wages) & $47,069.6$ & 8.4 \\
\hline Labor requirements (h/cow) & 97.2 & Capital & $501,235.0$ & 88.9 \\
\hline Family members $(h /$ cow) & 48.2 & Variable & $374,053.2$ & 66.4 \\
\hline Hired workers $(h /$ cow) & 49.0 & Fixed & $127,181.8$ & 22.5 \\
\hline Hourly wage $(€ / \mathrm{h})$ & 3.83 & Total & $\mathbf{5 6 3 , 6 9 5 . 5}$ & $\mathbf{1 0 0 . 0}$ \\
\hline
\end{tabular}


EU-countries, as the new framework practically reduced the perishability of the product. As a result, from March 2016 farms have suffered very high cuts in cow milk producer prices, which poses, for once more, a serious threat to their survival.

\subsection{Sheep and goat transhumance in Central Greece (Study 2)}

Transhumance involves the movement of flocks - often along with farm families - towards highland communities, where they spend approximately 4-6 months in the summer. Data from the Greek Payment Organization (OPEKEPE) do not demonstrate significant changes in the number of transhumant farms after the strike of the crisis and definitely not a reduction in the numbers of animals reared (2009-2014), which would reveal a structural diversification path. The results reported here concern a questionnaire survey which took place in Thessaly, where $35 \%$ of the reared animals and $30 \%$ of transhumant farms are situated. Labor expenses account for more than $25 \%$ for the average farm (Table 3 ).

Despite the undeniable family character of the farms, almost $25 \%$ of the total labor requirements are covered by migrants. An important characteristic of labor in these farms lies on its quality elements. Although, in general, all family members work together with hired workers, more often than not there is an intended or unintended work plan allocating tasks among the available workforce, which is based on the special skills and the practical knowledge of each person. Hired workers are the ones responsible for grazing, feeding and cleaning. Males, who are usually the heads of the farms, are involved in the preparation of feedstuff, in animal health tasks (e.g. vaccinations), in feeding and in the transportation of products, while they spend much time in bureaucratic and economic management tasks, communication and sales. Another important feature involves milking, as the heads of farms prefer to do it with experienced family members (e.g. their fathers or brothers); some of them stated that they did not trust hired workers to do the milking without supervision. When it comes to women, their role is supporting e.g. during birth season and weaning, except for cheese-making. Traditional tacit knowledge about cheese-making is passed from elder female family members to the younger - which is not only a Greek phenomenon, see for example Morris and Evans (2001) - so women are responsible for a product which adds value to raw milk and supports family income. Although the average farm earns only $5 \%$ of its gross revenue from cheese sales, this activity is particularly important for medium-sized farms.

\subsection{Intensive sheep farming in Evros (Study 3)}

The third survey was conducted in 2010 and repeated in 2014 on a sample of 41 lowland sheep farms in Northern Evros, in the North-Eastern part of the country. These farms were predominantly intensive or semi-intensive, modernized through funding opportunities of the CAP, like many other farms in the whole country. After 2005, large farms emerged rearing improved sheep breeds and adopting technological (modern buildings, milking machines) and management innovations. They relied on hired labour, mainly of migrants, as spouses remained in charge of their farm household duties and younger family members looked for off-farm jobs or left homes to study in other parts of the country. The outburst of the crisis was the cut-off point. Under the combined effects of several unexpected adverse

Table 3 - Main technical and economic performance indicators of transhumant farms in Thessaly.

\begin{tabular}{|l|c|l|c|c|c|}
\hline & & & $\epsilon$ & $\epsilon /$ ewe & $\%$ \\
\hline Average flock size (ewes and dams) & 494,00 & Land (Rent) & 2865,20 & 5,8 & 3,4 \\
\hline Milk production (ton./year) & 47,40 & Labor (Wages) & 22032,40 & 44,6 & 26,0 \\
\hline Labor requirements (h/ewe) & 13,50 & Capital & 59675,20 & 120,8 & 70,6 \\
\hline Family members (h/ewe) & 9,80 & Variable & 49103,60 & 99,4 & 58,1 \\
\hline Hired workers (h/ewe) & 3,70 & Fixed & 10571,60 & 21,4 & 12,5 \\
\hline Hourly wage (€/h) & 3,30 & Total & $\mathbf{8 4 5 7 2 , 8 0}$ & $\mathbf{1 7 1 , 2}$ & $\mathbf{1 0 0 , 0}$ \\
\hline
\end{tabular}


Table 4 - Main technical and economic performance indicators of intensive lowland farms in Northern Evros.

\begin{tabular}{|l|c|c|l|c|c|c|c|}
\hline & 2010 & 2014 & & 2010 & & 2014 & \\
\hline Average flock size (ewes) & 243,80 & 218,60 & & $\epsilon$ & $\%$ & $\epsilon$ & $\%$ \\
\hline Milk production (ton./year) & 34,80 & 28,10 & Land (Rent) & 4949,1 & 6,4 & 3585,0 & 4,8 \\
\hline Labor requirements (h/ewe) & 27,80 & 28,80 & Labor (Wages) & 18626,3 & 23,9 & 18493,6 & 24,5 \\
\hline Family members (h/ewe) & 20,60 & 26,80 & Capital & 54196,7 & 69,7 & 53338,4 & 70,7 \\
\hline Hired workers (h/ewe) & 7,20 & 2,00 & Variable & 28890,3 & 37,2 & 28024,5 & 37,2 \\
\hline Hourly wage (€/h) & 2,75 & 2,94 & Fixed & 25306,4 & 32,5 & 25313,9 & 33,5 \\
\hline Marginal product of labor $(€ / \mathrm{h})$ & 2,27 & 3,21 & Total & $\mathbf{7 7 7 7 2 , 2}$ & $\mathbf{1 0 0 , 0}$ & $\mathbf{7 5 4 1 7 , 0}$ & $\mathbf{1 0 0 , 0}$ \\
\hline
\end{tabular}

outcomes, the lowland farmers of Evros saw their investments completely go the other way, especially when dairy companies ceased to be consistent in milk payments. As a result, in 2015 the number of farms had diminished by 33.5 per cent compared to 2010, and the number of animals had fallen to $37,874(-44.7 \%)$.

Table 4 summarizes all the developments in the sampled farms from 2010, when the crisis started to have an impact on farms, to 2014, when repercussions were obvious. Under the suffocating lack of liquidity, farmers tried to substitute hired labor in order to reduce costs. Consequently, in 2014, during the crisis, family members - especially women - were recruited: while in $201026 \%$ of labor was offered by hired workers, in 2014 this percentage would not exceed $7 \%$ and a female member of the family would work regularly or part-time in 36 of the 41 farms. Despite the addition of women, farms kept their "masculine" identity, as men continued to work on the same tasks as before the crisis, while women mainly helped in milking or in grazing, thus taking over the duties of hired workers. However, they were also involved in non-regular chores for example cleaning or during the birth season or in taking care of young lambs, thus revealing the "emotional" and specialized elements of their contribution to their farms but also their specific skills. As a result, the marginal product of labor was significantly increased by more than 40 per cent from $2010(2.27 € / h)$ to $2014(3.21 € / h)$.

\subsection{Extensive sheep and goat production of the Muslim minority (Study 4)}

The fourth survey concerns the Pomak minority of Evros. The Pomaks constitute a significant part of the Greek Muslim minority and almost 2,000 of them live in the Prefecture of Evros (ELSTAT, 2011). They are characterized by language, traditional attire, customs and even their physical characteristics. Their way of life is partially dependent on household production and consumption and very tightly linked to primary production, of which livestock farming is the most important. They mainly rear sheep and goats and, to a lesser extent, cattle. Farms are pastoralist and small-sized and rear autochthonous breeds while only very few of them made - marginal only - capital investments. In this traditional society women play a central role, which extends to many domains including a long-standing tradition of informal cooperation in wildfire prevention and confrontation, reciprocal farm work, cultural and religion-based festivals etc. The wife is involved in farm operation, providing manual labor or becoming the manager of the farm when the husband migrates to work as a sailor or worker, thus leaving the rural community for long periods. Nonetheless, because of the crisis and widespread unemployment, many husbands have now returned to their farms; still, it is the members of the family that run the farm and women have maintained their essential role, demonstrating that the character of the Pomak livestock production system has not been abolished after the crisis. These considerations are depicted in Table 5.

Labour requirements are relatively low $(18.8 \mathrm{~h} /$ animal) compared to the other sheep and goat production systems. Another interesting feature lies in the fact that farm families are the sole source of labour; in particular, women continue to do most of the work, as in the past, despite the fact that husbands also contribute. The quality elements of the female work are also illustrated in Table 5. Wom- 
Table 5 - Labour availability and requirements in the Pomak livestock production system.

\begin{tabular}{|l|c|c|c|c|c|c|c|c|c|}
\hline & \multirow{2}{*}{$\begin{array}{c}\text { Family } \\
\text { labor }\end{array}$} & \multirow{2}{*}{$\begin{array}{c}\text { Husband } \\
\text { labor }\end{array}$} & \multirow{2}{*}{$\begin{array}{c}\text { Wife } \\
\text { labor }\end{array}$} & \multirow{2}{*}{$\begin{array}{c}\text { Other } \\
\text { members }\end{array}$} & \multicolumn{6}{|c|}{ Wilking } & Feeding & Cleaning & Grazing & Other \\
\hline Hours/year & 6231 & 2402 & 2865 & 964 & & & & & \\
\hline Hours/ewe/year & 18,8 & 7,3 & 8,7 & 2,9 & & & & & \\
\hline H/day & & & & & 3,2 & 1,7 & 1,7 & 0,4 & 0,8 \\
\hline
\end{tabular}

en perform everyday tasks (milking, feeding and cleaning) and manufacture cheese and meat products, which are, unlike the case of transhumance, consumed within the household and are rarely directed towards markets.

\section{Synthesis and discussion of the empirical findings}

The findings reported here, also summarized in Table 6, highlight important questions about the use and the role of labor in the Greece of crisis. A recent study by Psycharis et al. (2014) reported that the regions whose agricultural sectors were most benefited before the crisis have not been able to sustain these benefits after the crisis. The analysis in this study did not fully confirm this finding: dairy cow farms managed to maintain their family character and to use hired labor as a tool for expansion. Their success can be attributed to the adoption of an entrepreneurial rationale, useful and rational investments, the adoption of new technologies and innovative techniques and the development of a dynamic stance against the crisis. Marketing innovations could also be important, including exam- ples of dairy farm Cooperatives such as Thes-Gala in Thessaly which established automatic cow milk selling machines in many parts of northern Greece. An active strategy would generally be pertinent to the large intensive dairy cow farms and also to the intensive sheep farms of Evros, but their different approaches in the implementation of their investments was the element that made their paths diverge. As a result, dairy cow farms undertook active strategies without diversifying their operational pattern while sheep farms of Northern Evros adopted a structural diversification approach and passive strategies, including reduced operation and cooperation.

It is difficult to discern whether hired labor is still essential for intensive farms: active strategies against the crisis presuppose hired labor and lead to better financial results, as in the example of dairy cow farms. In a broader sense, active strategies contributed to maintain optimism in the operation of farms, an element which is actually missing from the Greek economy and constitutes one of the factors that does not permit the country to leave behind the vicious cycle of repression.

Table 6 - Basic characteristics of strategies against the crisis within the four studies.

\begin{tabular}{|l|c|c|c|c|c|}
\hline & $\begin{array}{c}\text { \% labor in total } \\
\text { costs /\% hired } \\
\text { labor in total } \\
\text { labor }\end{array}$ & $\begin{array}{c}\text { Investments } \\
\text { (Past/ } \\
\text { Present) }\end{array}$ & $\begin{array}{c}\text { Traditional knowledge/ } \\
\text { Specialized skill } \\
\text { requirements }\end{array}$ & $\begin{array}{c}\text { Family } \\
\text { character }\end{array}$ & $\begin{array}{c}\text { Strategies- } \\
\text { Diversification } \\
\text { paths }\end{array}$ \\
\hline Dairy cattle & $8,4 / 50,4$ & $\begin{array}{c}\text { Rational/ } \\
\text { Ongoing }\end{array}$ & Little/High & Moderate & Active- None \\
\hline Intesive sheep & $24,5 / 25,8-6,9$ & $\begin{array}{c}\text { Irrational/ } \\
\text { None }\end{array}$ & $\begin{array}{c}\text { Medium (women } \\
\text { labor)/High }\end{array}$ & Increasing & $\begin{array}{c}\text { Passive - Structur- } \\
\text { al diversification }\end{array}$ \\
\hline Pomak sheep & $>35 / 0$ & Few/None & High/Medium & Very high & Passive - None \\
\hline Transhumant & $26,1 / 27,0$ & Few/Few & High/High & High & $\begin{array}{c}\text { Passive - } \\
\text { Agricultural } \\
\text { diversification }\end{array}$ \\
\hline
\end{tabular}


On the other hand, passive strategies in lowland sheep farms of Evros relied on the farm family implying more rational use of own resources which increased labor productivity. The fact that entrepreneurial farms tended to face the crisis by re-distributing specific tasks among workers was also pointed out by Karelakis et al. (2013). Farms returned to their roots and rediscovered the merits of family labor, thus taking advantage of their tacit knowledge and special skills. It seems that the active involvement of family members and the recently established Cooperative "Thrakon Amnos" could provide farms with the necessary solutions against financial asphyxiation and would ensure their survival. Actually the Cooperative is responsible for milk and meat sales of more than 110 local sheep and goat lowland farms. The Cooperative has undertaken some innovative commercial strategies, including the establishment of automatic milk selling machines (ATMs) in a city nearby (Alexandroupoli), while it has adopted a remuneration system for farmers based on the quality rather than the quantity of milk sold through the Cooperative.

On the other hand, extensive systems exhibited various levels of response to the crisis. The example of the Pomak society is on the extreme end, proclaiming a pattern of a relatively closed society, with few linkages to other societies, which only opened up to markets and investments at a very low degree. Pomak farms safeguarded their family character and never resorted to hired labor, which permitted them not to suffer intense repercussions from the crisis. Women maintained their primary role, because the return of men to the farm was only provisional, as they are always looking for off-farm employment ("income" diversification). Effectively, the "feminine" identity of the farm was not altered. The persistence of cooperation and reciprocal labor in the Pomak society also provides an explanation of its performance through the crisis. Furthermore, the persistence of the Pomak system lies on its pluriactive character, as the existence of off-farm incomes has been found as a stabilizing factor in Greek agriculture (Karanikolas and Zografakis, 2008; Kasimis and Papadopoulos, 2013). These off-farm incomes could be further supported through a strategy focusing on the uniqueness of the dairy products of these farms (e.g. through a certification scheme) which would not only add value to the product but would induce other related activities such as distribution, retail sales etc.

Transhumance, although a semi-extensive system, exhibited differences from the Pomak system. Historically, one of the main features of the transhumant system has been its ability to maintain its traditional character while being able to survive crises and unexpected conditions. Farms not only kept their family character and continued to employ hired workers whenever needed, but they also maintained a relatively same profile of labor management, by allocating tasks to workers other than those allocated to auxiliary family members. Their diversified production pattern, accommodating a broad variety of final products (milk, meat, cheese), was the factor which helped them survive the crisis relatively easily. They followed an agricultural diversification pattern, investing on their existing skill and tacit knowledge i.e. on-farm cheese production. Especially medium-sized farms capitalized on traditional cheese-making, in order to reduce their dependence from markets. This pattern was not suitable either for small farms, which did not have available labor to accommodate that, or for large farms, which, even if they produced cheese, it would still stand for a very small proportion of their total milk production and would only bring marginal benefits to the profitability of the farm. A recent study by López-i-Gelats et al. (2016) revealed that this agricultural diversification path is common for agro-pastoral systems in Europe (e.g. changes in feeding management); although their meta-analysis did not include the crisis as a driver of the system and mainly environmental and climate-change factor were considered, the authors reported a trend for income and structural diversification in some instances, which has not been verified by the findings of the Greek transhumance study.

A general observation that can be deducted from this study is that the active participation of women in farm management is linked to better performance in dealing with crises. Valvidia and Gilles (2001) pointed out that the degree of participation of women in farm management affects family well-being and this study is in accordance 
with this statement. Although straightforward linkages and correlations cannot be founded, as the development of the bundle of farm strategies is a complicated issue rather than an one-factor outcome, it is obvious that the extensive systems, within which women have more active roles, have achieved better performance during the crisis, whereas the intensive systems, where women were ruled out from farm management, exhibited worse responsiveness against the crisis. In addition, in the Evros intensive sheep farming case, not only did women contribute to the reduction of hired labor, but their active commitment considerably increased labor productivity.

\section{Conclusions}

The study presented in this paper revealed the strategies that livestock farmers undertake in times of crisis. Based on these findings the question is raised: is labor still a prerequisite for the development of the Greek livestock sector and under which development pattern could family labor suffice? It can be supported that the emergence and maintenance of intensive, highly productive and market-integrated livestock farms in Greece is not utopian. Even under the crisis, unpaid family labor cannot be the only source of labor for farms; hired labor can also be used in order to support investments in intensive farms, if and only if certain prerequisites are met, including the rational assessment of these investments and the use of hired labor only when farms become so large that family members exhaust their possibilities.

The adoption of an extensive production pattern and the operation of farms away from markets constitute a reliable alternative ensuring the temporal reproduction of farms, as was proven here. So, is the future of livestock farming related to an "extensive" lifestyle - even in isolation - which has been abandoned for decades? And also, considering that hired labor is an alternative only for intensive entrepreneurial production patterns, should a family be a "slave" within its own extensive farm? Can't its members flourish outside its boundaries? Last but not least, should the "one-man-farm" model (Bye, 2009) be revisited now, under a new, volatile and uncertain environment, as has been proposed by Wallance (2002)? These issues need to be better addressed in the future, either through gender-based studies and policy-related approaches or by more detailed economic studies focusing on the actual roles of all sources of labor (men, women, farm children, hired workers, migrants) in farm management within different contexts before and after the crisis.

\section{References}

Bharadwaj L., Findeis J.L. and Chintawar S., 2013. Motivations to work off-farm among US farm women. The Journal of Socio-Economics, 45: 71-77.

Bye L.M., 2009. "How to be a rural man": young men's performances and negotiations of rural masculinities. Journal of Rural Studies, 25: 278-288.

Casini L., Ferrari S., Lombardi G., Rambolinaza M., Sattler C. and Waarts Y., 2004. Research report on the analytic multifunctionality framework. Report of the FP6 Research Project MEA-Scope.

Cessna J., 2010. Situation and Outlook for the U.S. Dairy Industry. Agricultural Outlook Forum, retrieved on October 2016 from: http://www.usda. gov/oce/forum/2010_Speeches/Speeches/DairyOutlook2010.pdf.

Chatziminaoglou I., 2001. Sheep and goats in Greece and internationally. Giahoudi-Giapouli, Thessaloniki (in Greek).

Donaldson S., 2011. From Neighbors to Migrants: The Shifting Organization of Agricultural Labor in East Tennessee. Anthropology of Work Review, 32(1): 9-20.

ELSTAT (Greek Statistical Authority), 2011. Population census results. Athens.

ELSTAT (Greek Statistical Authority), 2015. Available online at: http://www.statistics.gr/documents/20181/ 839b30a4-4812-4846-8d86-8c19ca61d2d3.

Franks J.R., 1998. Predicting financial stress in farm businesses. European Review of Agricultural Economics, 25: 30-52.

Goussios D., 2011. Le regain de l'intérêt du secteur agricole en Grèce: Tendance lourde ou passagère? Edité par la Mission Agrobiosciences. http://www. agrobiosciences.org/IMG/pdf/Reaction_Goussios agriculture_grecque_Juin_2011.pdf.

Gunderson L.H., 2003. Adaptive dancing: interactions between social resilience and ecological crises. In: Berkes F., Colding J. and Folke C. (eds.). Navigating Social Ecological Systems: building resilience for complexity and change. Cambridge: Cambridge University Press, 33-52. 
Guri F., Jouve A.M. and Dashi E., 2014. L'impact de l'exode rural sur les stratégies d'utilisation du foncier agricole dans le Nord-est albanais. New Medit, 13(1): 22-30.

Herron R.V. and Skinner M.W., 2012. Farmwomen's emotional geographies of care: a view from rural Ontario. Gender, Place and Culture, 19(2): 232-248.

Holzner B.M., 2008. Agrarian restructuring and gender - designing family farms in Central and Eastern Europe. Gender, Place and Culture, 15(4): 431-443.

Ingrand S., Magne M.A., Chia E., Moulin C.H., Dedieu B., Lémery B. and Cerf M., 2006. Non material resources mobilised by farmers and flexibility of livestock farming systems: two concepts linked to decision making and sustainability. Proceedings of the 57th Annual Meeting of the European Association for Animal Production, Antalya, Turkey, 17-20.

Jervell A.M. and Jolly D.A., 2003. Beyond food: Towards a multifunctional agriculture. Norwegian Agricultural Economics Research Institute, Oslo, Norway.

Jetté-Nantel S., Freshwater D., Katchova A.L. and Beaulieu M., 2011. Farm income variability and off-farm diversification among Canadian farm operators. Agricultural Finance Review, 71(3): 329-346.

Karanikolas P. and Martinos N., 2012. Greek agriculture facing crisis: Problems and prospects. Available online at: http://ardinrixi.gr/archives/3811 (in Greek).

Karanikolas P. and Zografakis S., 2008. Greek Farm Households: Income inequality, poverty and distributional impact of farm income. Social Cohesion and Development, 3(1): 27-44.

Karelakis C., Abas Z., Galanopoulos K. and Polymeros K., 2013. Positive effects of the Greek economic crisis on livestock farmer behaviour. Agronomy for sustainable development, 33(3): 445-456.

Kasimis C. and Papadopoulos A.G., 2005. The Multifunctional Role of Migrants in Greek Countryside: Implications for Rural Economy and Society. Journal of Ethnic and Migration Studies, 31(1): 99-127.

Kasimis C. and Papadopoulos A.G., 2013. Rural transformations and family farming in contemporary Greece. Agriculture in Mediterranean Europe: Between Old and New Paradigms. Research in Rural Sociology and Development, 19: 263-294.

Kazakos P., 2006. Social capital and collective action: implications on social structures, performance and reform. Greek Exp. Sci. Soc. 16, 107-138 (in Greek).

Lemery B., Ingrand S., Dedieu B. and Dégrange, B., 2005. Agir en situation d'incertitude: le cas des éleveurs de bovins allaitants. Économie rurale. Agricultures, alimentations, territoires, 288: 57-69.
López-i-Gelats F., Fraser E.D., Morton J.F. and Rivera-Ferre M.G., 2016. What drives the vulnerability of pastoralists to global environmental change? A qualitative meta-analysis. Global Environmental Change, 39: 258-274.

Loukopoulos D., 1930. Pastoralism in Roumeli. Sideris, Athens, Greece (in Greek).

Maroukis T., 2013. Economic crisis and migrants' employment: a view from Greece in comparative perspective. Policy Studies, 34(2): 221-237.

Marta-Costa A.A., 2010. Sustainability study for the rearing of bovine livestock in mountainous areas. New Medit, 9(1): 4-12.

Meert H., Van Huylenbroeck G., Vernimmen T., Bourgeois M. and van Hecke, E., 2005. Farm household survival strategies and diversification on marginal farms. Journal of Rural Studies, 21(1): 81-97.

Milestad R., Dedieu B., Darnhofer I. and Bellon S., 2012. Farms and farmers facing change: The adaptive approach, In: Darnhofer I., Gibbon D. and Dedieu B. (eds.), Farming Systems Research into the 21st Century: The new Dynamic. Dordrecht: Springer, 365-385.

Morris C. and Evans N., 2001. Cheese Makers Are A1ways Women': Gendered representations of farm life in the agricultural press. Gender, Place \& Culture, 8(4): 375-390.

Nori M., 2016. Shifting Transhumances: migration patterns in Mediterranean pastoralism. La Lettre de veille di CIHEAM, 36.

Nori M. and de Marchi V., 2015. Pastorizia, biodiversità e la sfida dell'immigrazione: il caso del Triveneto. Culture della Sostenibilità, VIII/15.

Nori M. and Ragkos A., 2017. Migrant shepherds and their role for sustainable pastoralism in Greece. Proceedings of the 5th Pan-Hellenic Congress in Technology of Animal Production (3 February 2017), 115-117.

Paraskevopoulos C., 2006. Social capital and public policy in Greece. Sci. Soc., 16: 69-106.

PASEGES, 2013. Recent Developments in the Agricultural Economy of Greece. Athens (in Greek).

Psycharis Y., Rovolis A., Tselios V. and Pantazis P., 2014. Economic crisis and regional development in Greece. Région et Développement, 39: 67-85.

Reyes-García V., Aceituno-Mata L., Calvet-Mir L., Garnatje T., Gómez-Baggethun E., Lastra J.J., Ontillera R., Parada M., Rigat M., Valles J., Vila S. And Pardo-de-Santayana M., 2014. Resilience of traditional knowledge systems: The case of agricultural knowledge in home gardens of the Iberian Peninsu1a. Global Environmental Change, 24: 223-231.

Saugeres L., 2002. Of tractors and men: Masculinity, technology and power in a French farming community. Sociologia Ruralis, 42(2): 143-159. 
Theodoridis A. and Psychoudakis A., 2008. Efficiency measurement in Greek dairy farms: stochastic frontier vs. data envelopment analysis. International Journal of Economic Sciences and Applied Research, 1(2): 53-66.

Trauger A., 2004. "Because they can do the work": women farmers in sustainable agriculture in Pennsylvania, USA. Gender, Place \& Culture, 11(2): 289-307.

Valdivia C. and Gilles J., 2001. Gender and resource management: Households and groups, strategies and transitions. Agriculture and Human Values, 18: 5-9. Von Glasenapp M. and Thornton T.F., 2011. Tradition- al ecological knowledge of Swiss alpine farmers and their resilience to socioecological change. Human Ecology, 39(6): 769-781.

Wallance C., 2002. Household strategies: their conceptual relevance and analytical scope in social research. Sociology, 36(2): 275-292.

Zaiceva A. and Zimmermann K.F., 2016. Returning home at times of trouble? Return migration of EU enlargement migrants during the crisis. In: Kahanec M. and Zimmermann K.F. (eds.), Labor Migration, EU Enlargement, and the Great Recession. Berlin-Heidelberg: Springer, 397-418. 